\title{
ИЗМЕНЕНИЯ СОДЕРЖАНИЯ Р53- И ВСL-2-ПОЗИТИВНЫХ НЕЙРОНОВ В СЕНСОМОТОРНОЙ КОРЕ ГОЛОВНОГО МОЗГА БЕЛЫХ КРЫС
}

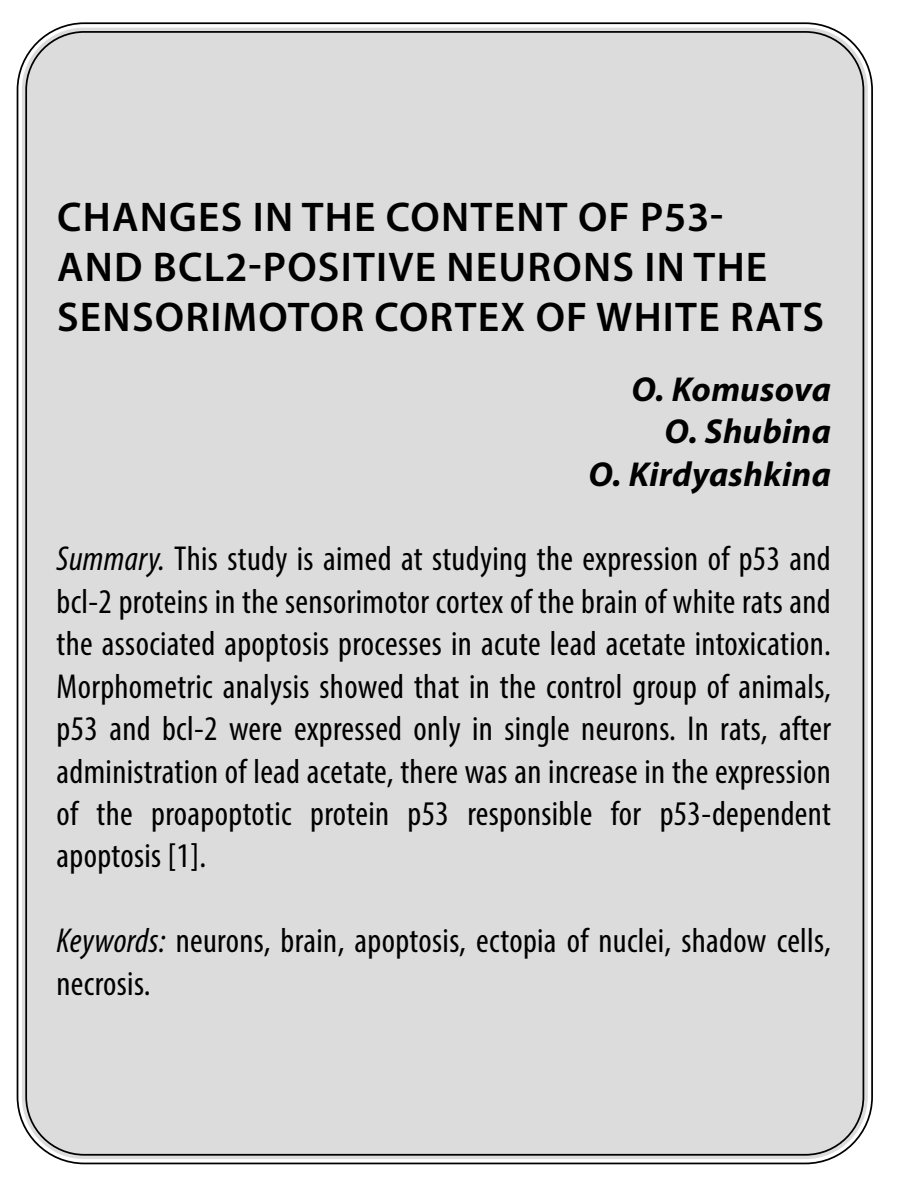

\section{Введение}

и зучение структурных основ деятельности головного мозга в норме и при различных воздействиях является традиционным и важнейшим направлением современной нейроморфологии. Несмотря на большое количество работ, посвященных функциональной нейрогистологии, многие вопросы этой важной для биологии и медицины проблемы, прежде всего в отношении структур центральной нервной системы, освящены недостаточно. Остаются невыясненными вопросы касающиеся влияния свинца на процессы гибели нейронов головного мозга в процессе апоптоза и некроза.

\section{Цель выполнения исслеАования}

Выявить закономерности изменения содержания p53- и bcl2-позитивных нейронов в сенсомоторной коре головного мозга белых половозрелых крыс при воздействии ацетата свинца.
Комусова Ольга Ивановна

К.б.н., ФГБОУ ВО «Мордовский государственный педагогический университет имени М.Е. Евсевьева»

(2. Саранск)

timoshkina03@mail.ru

Шубина Ольга Сергеевна

Д.б.н., профессор, ФГБОУ ВО «Мордовский государственный педагогический университет имени М.Е. Евсевьева» (2. Саранск) os.shubina@mail.ru

Кирдяшкина Ольга Викторовна Aспирант, ФГБОУ ВО «Мордовский государственный педагогический университет имени М.Е. Евсевьева»

(2. Саранск)

Sigma.ov@mail.ru

Аннотация. Данное исследование направлено на изучение экспрессии белков p53 и семейства bcl-2 в сенсомоторной коре головного мозга белых крыс и связанных с ними процессов апоптоза при острой интоксикации ацетатом свинца. Морфометрический анализ показал, что в контрольной группе животных р53 и bcl-2 экспрессировались только в единичных нейронах. У крыс после введения ацетата свинца отмечалось увеличение экспрессии проапоптического белка р53 отвечающего за р53-зависимый апопт0з [1].

Ключевые слова: нейроны, головной мозг, апоптоз, эктопия ядер, клетки-тени, некроз.

\section{Материалы и методы исследования}

Данное исследование проведено на 50 белых беспородных половозрелых крысах-самцах, которые были разделены на 2 группы. Контрольная группа находилась на общем режиме вивария. Опытная группа получала в течение 7 суток перорально ацетат свинца $\mathrm{Pb}\left(\mathrm{CH}_{3} \mathrm{COO}\right)_{2} \times 3 \mathrm{H}_{2} \mathrm{O}$ в дозе $45 \mathrm{mг} /$ кг/сутки (в пересчете на свинец).

В работе применялись высокоинформативные методы гистологического, морфометрического, иммуногистохимического и статистического анализа, направленные на выяснение закономерностей структурно-функциональной реорганизации нейрональных популяций в сенсомоторной коре экспериментальных животных в условиях острого воздействия ацетатом свинца [3].

Гистологические препараты головного мозга получали путем фиксации материала в 10\% растворе ней- 
Таблица 1. Результаты сравнительного изучения цитоархитектоники сенсомоторной коры головного мозга у крыс $(\mathrm{M} \pm \mathrm{s})$

\begin{tabular}{|l|l|l|}
\multirow{2}{*}{ Показатели } & \multicolumn{2}{l|}{ Содержание нейронов, в 1 мм } \\
\cline { 2 - 3 } & Контроль & Опыт \\
\hline Общая численная плотность нейронов коры & $214795 \pm 10739$ & $123983 \pm 6199^{*}$ \\
\hline Содержание нормохромных нейронов & $203774,50 \pm 1088$ & $63555,94 \pm 3177^{*}$ \\
\hline Содержание измененных нейронов & $11020,50 \pm 110,20$ & $60427,15 \pm 3021^{*}$ \\
\hline Ядерно-цитоплазматическое отношение & $0,43 \pm 0,02$ & $0,25 \pm 0,01^{*}$ \\
\hline
\end{tabular}

Примечание: * - достоверно по отношению к контролю $\mathrm{P} \leq 0,01$.

Таблица 2. Содержание p53, bcl-2 - позитивных нейронов в сенсомоторной коре головного мозга у крыс (в 100 полях зрения на группу) $(\mathrm{M} \pm \mathrm{s})$

\begin{tabular}{|l|l|l|}
\hline Показатели & Контроль & Опыт 1 \\
\hline p53- позитивные нейроны & $1072,94 \pm 21$ & $9205 \pm 306^{*}$ \\
\hline bcl-2-позитивные нейроны & $1075 \pm 53$ & $6097,04 \pm 254^{*}$ \\
\hline
\end{tabular}

Примечание: * - достоверно по отношению к контролю $\mathrm{P} \leq 0,01$.

трального формалина на фосфатном буфере (фирма «Биовитрум», Санкт-Петербург) с последующим окрашиванием гематоксилином-эозином, метиленовым синим по Нисслю [4].

Исследование гистологических препаратов проводилось с помощью цифрового микроскопа МТ 4000 Series Biological Microscope с программным обеспечением для анализа изображений «Bio Vision Version 4.0», бинокулярного светового микроскопа (Axioscop «Carl Zeiss», Германия), цифровой системы видеодокументирования высокого разрешения Nikon DS-5Mc. Фотосъемку препаратов производили с помощью встроенной камеры, с последующей обработкой изображения в Abode Photoshop Elements 11.

Иммуногистохимические реакции проводили на серийных парафиновых срезах иммунопероксидазным методом с использованием системы визуализации Dako (Дания), разведение 1:100. Определялась экспресия белков p53 и bcl-2. Реакцию оценивали по содержанию меченых клеток и по плотности гранул.

\section{Результаты и обсужление}

Гистологическое исследование показало, что после введения ацетата свинца в сенсомоторной коре развивались повреждения нервной ткани - острое набухание нейронов, эктопия ядер, гиперхроматоз, распад ядра и ядрышка, клетки-тени, гиперхромные сморщенные и несморщенные нейроны.

По данным морфометрического исследования, между изученными группами контроль и опыт имелись статистически значимые отличия по всем показателям (табл. 1).

При сравнительном анализе общей численной плотности нейронов сенсомоторной коры в опытной группе, по сравнению с контрольной группой отмечалось снижение на 42,2\% ( $\leq \leq 0,01)$. Так же, отмечалось снижение содержания нормохромных нейронов на $68,8 \%(p \leq 0,01)$ и обнаруживалось увеличение содержания измененных нейронов в 5,5 раза $(p \leq 0,01)$. После введения ацетата свинца животным опытной группы было обнаружено статистически значимое снижение индекса ядерно-цитоплазматического отношения на $41,8 \%(p \leq 0,01)$, по сравнению с группой контроля (табл. 1).

Исходя из литературных данных, известно, что воздействие острой свинцовой интоксикации приводит к гибели клеток головного мозга не только в результате некроза, но и запуска в них процессов апоптоза [2].

Появившиеся гиперхромные сморщенные нейроны (пикноморфные) представляют из себя многообразные патологически измененные клетки с гиперхромным пикнотичным ядром и плотной, бесструктурной цитоплазмой, лишенной базофильных глыбок вещества Ниссля. Подобные структурные изменения могут быть проявлениями коагуляционного некроза нервной клетки, а также апоптоза до фазы ее дезинтеграции на остаточные апоптозные тела. Вероятно, эти изменения и являются причиной гибели нейронов. Определить возможность преобладания одного из этих процессов в конкретном нейроне очень сложно. 


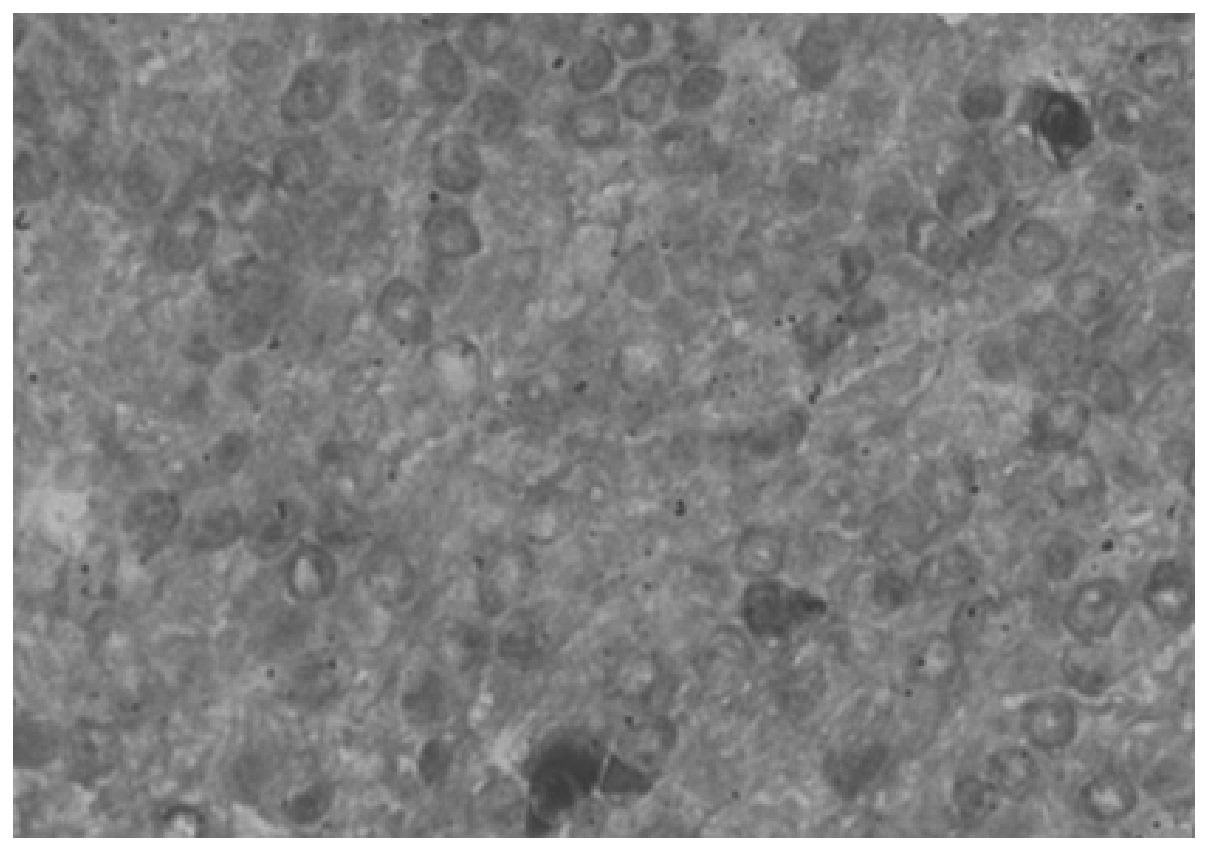

Рис. 1. р53-позитивные нейроны в сенсомоторной коре головного мозга крыс (контроль). Иммуногистохимическая окраска на р53. Об.40× ок. 10.

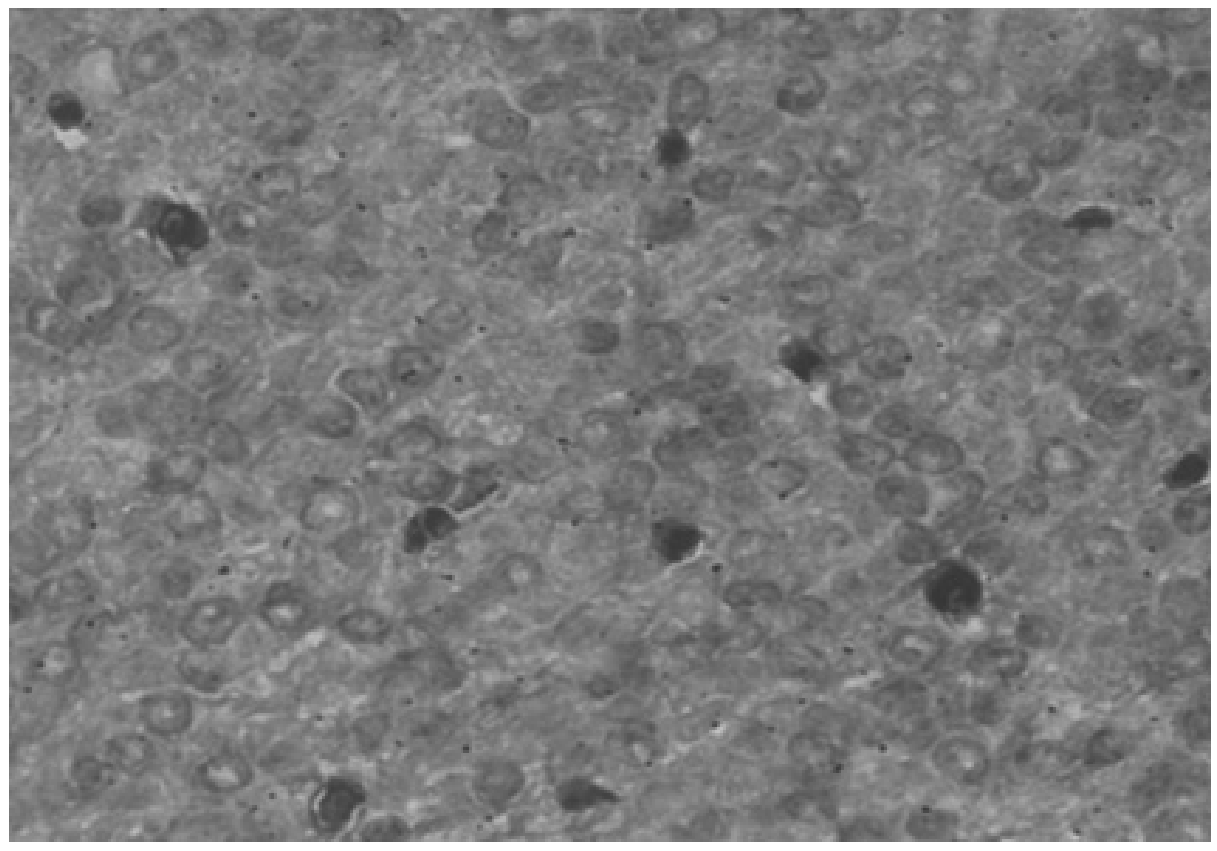

Рис. 2. р53-позитивные нейроны в сенсомоторной коре головного мозга крыс (опыт 1). Иммуногистохимическая окраска на р53. Об.40× ок. 10.

В пользу активации механизмов программированной клеточной гибели после интоксикации ацетатом свинца свидетельствовали данные проведенного иммуногистохимического анализа выявления проапоптотических стрессовых (p53) и анти- (bcl-2) белков.
Морфометрический анализ показал, что в контрольной группе животных p53 и bcl-2 экспрессировались только в единичных нейронах (рис. 1). У животных опытной группы после введения ацетата свинца наблюдалось статистически значимое увеличение меченых 
клеток (рис. 2). Количество р53- позитивных нейронов в опытной группе возросло в 8,6 раза, а bcl-2-позитивных нейронов в 5,6 раза $(p \leq 0,01)$, по сравнению с группой контроля (табл. 2, рис. 2).

Исходя из результатов проведенного анализа, можно заключить, что увеличение экспресии проапоптотического белка р53 указывает на активацию процессов апоптоза. По данным литературы, этот белок вызывает р53-зависимый апоптоз [5].

\section{Выво $\triangle \mathrm{b}$}

Увеличение экспрессии проапоптического белка p53 и более низкий уровень антиапоптического белка bcl-2 в нейронах сенсомоторной коры мозга при острой свинцовой интоксикации указывает на усиление повреждения и гибели нервных клеток за счет активации апоптоза наряду с преобладающей гибелью нервных клеток преимущественно путем коагуляционного некроза.

\section{ЛИТЕРАТУРА}

1. Орлянская Т.Я. Репатативные изменения в клеточных популяциях переднего мозга, мозжечка и спинного мозга в ответ на острое воздействие бытовых веществ / Т.Я. Орлянская, Г.А. Актушина, А.Д. Яценко // Морфология. — 2016. — СПб. ЭСКУЛАП.— 155 с.

2. Рыжавский Б.Я. Влияние свинца в молочном периоде онтогенеза на морфометрические, гистохимические и биохимические показатели развития головного мозга / Б.Я. Рыжавский, 0.А. Лебедько, И.Р. Еременко // Дальневосточный медицинский журнал. ख 2013. ख № 4. \С. $98 \bigotimes 105$.

3. Семченко В.В. Постаноксическая энцефалопатия / В.В. Семченко, С.С. Степанов, Г.В. Алексеева // М-во здравоохранения Рос. Федерации, Рос. акад. мед. наук. Сиб. отд-ние, НИИ общ. реаниматологии и др.-Омск: Ом. гос. мед. акад., 1999. — 446 с.

4. Семченко В.В. Гистологическая техника: учебное пособие / В.В. Семченко, СА. Барашкова, В.И. Ноздрин, В.Н. Артемьев. - 0мск-0рел: Омская областная типография. - 2006. - 290 с.

5. Culmsee C. p53 in neuronal apoptosis / C. Culmsee, M.P. Mattson // Biochem Biophys Res Commun. — 2005. — 331(3): 761-77.

(с) Комусова Ольга Ивановна ( timoshkina03@mail.ru ),

Шубина Ольга Сергеевна ( os.shubina@mail.ru ), Кирдяшкина Ольга Викторовна ( Sigma.ov@mail.ru ).

Журнал «Современная наука: актуальные проблемы теории и практики»

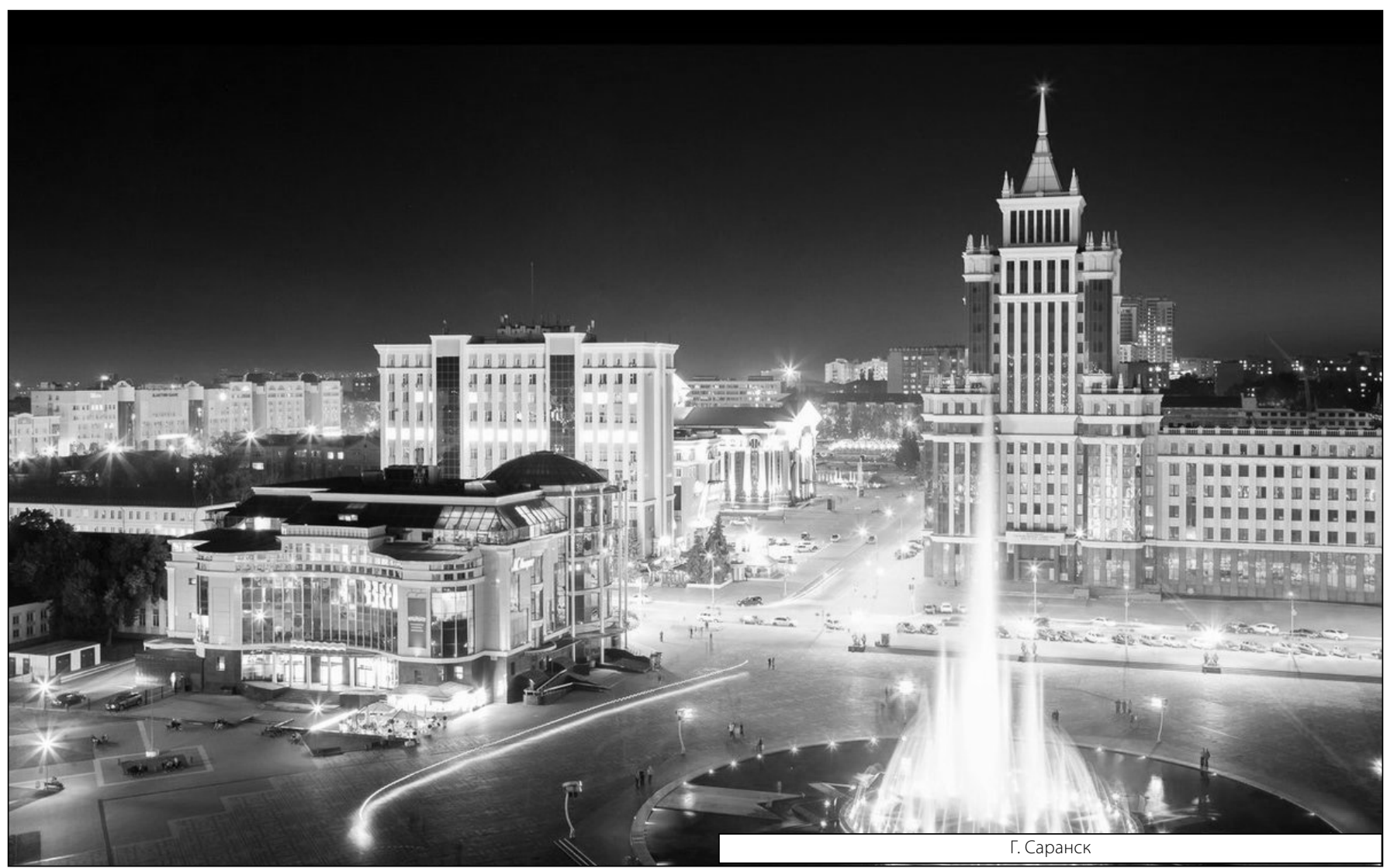

